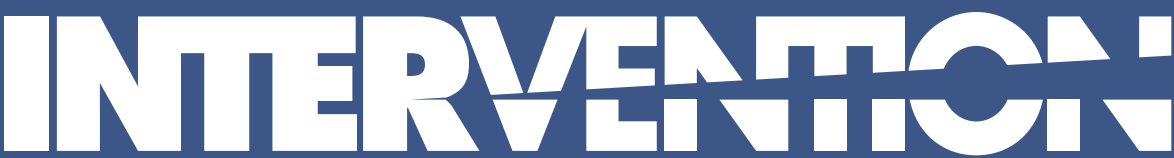

Journal of Mental Health and Psychosocial Support in Conflict Affected Areas 


\title{
Psychosocial support to foster social cohesion between refugee and host communities in Jordan
}

\author{
Paulina Acosta ${ }^{1}$ \& Nuria Chica ${ }^{2}$ \\ ${ }^{1}$ Psychologist, and Mental Health \& Child Care Practices Advisor for the Middle East at Action Contre la Faim, Paris, ${ }^{2}$ Psychologist and has worked with \\ Action Contre la Faim in Spain and Jordan, Jordan
}

\section{Abstract}

The internal conflict in Syria has displaced large numbers of the population into neighbouring countries since the uprising in 2011. The large influx of displaced people into Jordan poses great challenges to the international community as well as local authorities, with increasing competition for already scarce resources and services creating rising tensions between refugee and host communities. In this context, the non-governmental organisation, Action Contre la Faim, implemented a programme aimed at improving psychosocial wellbeing, fostering resilience and promoting positive interactions between the members of both communities. Through the participation of support groups within community-based organisations, dialogue was facilitated, and interactions took place in a safe and therapeutic environment. Participants reported improved perception of well-being and self confidence, as well as improved mutual understanding and communication, reduced isolation and the extension of social support, enhanced empathy and reduce prejudice.

Keywords: jordan, psychosocial support, refugees and vulnerable groups, social cohesion, syria crisis

\section{INTRODUCTION}

The Syrian uprising began in March 2011 with national protests against the ruling Ba'ath Party calling for the resignation of president Assad. The demonstrations quickly transformed into a civil war, and the death toll has reached more than 300,000 people, with 6.6 million displaced within Syria. By the end of 2016, 4.8 million were forced to seek refuge abroad (Amnesty International, 2016). The challenges to provide humanitarian relief to the population of Syria and the positioning of the neighbouring countries have led, since December 2011, to a massive influx of refugees into Lebanon, Turkey, Jordan, Iraq and Egypt.

\section{JORDAN: BACKGROUND AND SOCIO-ECONOMIC CONTEXT}

As of April 2017, more than 658,015 Syrian nationals were officially registered as refugees in Jordan (Syria Refugee Response Plan, page accessed April 27, 2017). In fact, Jordan has the highest ratio of refugees to local population in the region: around 3 million inhabitants out of 6 million are of foreign origin, mainly Palestinian, Iraqi and now Syrian. From October 2011 until July 2012, refugees settled among local communities, mainly in Amman and in the Northern Governorates, and no official camps were set up at that time. From July 2012 onwards, the government decided to place

\begin{tabular}{|l|l|}
\hline \multicolumn{2}{|c|}{ Access this article online } \\
\hline Quick Response Code: & Website: \\
& www.interventionjournal.org \\
\cline { 2 - 2 } & \\
\hline
\end{tabular}

refugees in camps (Regional Response Plan 5, UNHCR, 2013), mainly Za' atari, which in less than 12 months became the second biggest refugee camp worldwide. There was an influx of 2000 people per day. The decision was driven by the ongoing arrival coupled with the decreasing capacity of communities to absorb more people. However, $75 \%$ of refugees are living outside of the camps. In some cities of the Northern Governorates, the population has almost doubled. Until March 2012, the government had an 'open border policy', but in December 2015, the border was closed and remains closed to date.

Jordan has few internal resources (e.g. scarce water supply), its economy is based on tertiary services (such as banking and tourism) and it relies on oil imports for energy. Regional tensions have adversely affected both tourism and direct foreign investment. The country's economy has been struggling in a global recessive environment, and its ability to fully sustain a large and increasing refugee population has been at stake since the beginning of the crisis.

The Regional Response Plan 6 (United Nations, 2014) has marked a shift in thinking since late 2013 for all actors

Address for correspondence: Mrs. Paulina Acosta Del Rio, Action Contre la
Faim, Paris.
E-mail: paulinaacosta@zoho.com

This is an open access journal, and articles are distributed under the terms of the Creative Commons Attribution-NonCommercial-ShareAlike 4.0 License, which allows others to remix, tweak, and build upon the work non-commercially, as long as appropriate credit is given and the new creations are licensed under the identical terms.

For reprints contact: reprints@medknow.com

How to cite this article: Acosta, P. \& Chica, N. (2018). Psychosocial support to foster social cohesion between refugee and host communities in Jordan. Intervention, 16(2),147-153. 
involved, because it became imperative to target both refugee and host communities at the same time to align humanitarian response with longer-term development programming and to prioritise the stabilisation of the country through building resilience and the promotion of social cohesion as key strategic objectives (World Vision International, 2015). Indeed, the plan foresees a relief of pressure on services and resources, with a more significant support to Jordanian host communities, especially in urban areas.

\section{Humanitarian needs}

The non-governmental organisation (NGO) Action Contre la Faim (ACF, Action Against Hunger) started working in Jordan at the beginning of 2014, implementing projects to respond to the humanitarian crisis caused by the political conflict in Syria. According to the NGO's initial assessment, the majority of families that had moved to Jordan were fleeing growing insecurity or following attacks that had resulted in injuries or the death of family members, as well as the destruction of their homes. They were not able to carry any possessions, and left thinking that the violence would only last for a short time. Most people interviewed during the assessment were initially living in Za'atari camp, where they found life 'unbearable', given the high population density, poor sanitation and poor water quality, as well as an insecure environment. Living outside of the camp meant that they could have a 'normal life', their own housing, privacy and employment opportunities. However, it also meant greater expense for their basic needs, more competition for jobs and a greater feeling of isolation and exclusion, the longer their situation lasted (ACF, 2013).

Rental fees doubled throughout 2013, and Syrian suppliers have stopped supplying fuel for the markets of the Northern Governorates, which has led to the increasing prices of basic items for everyone. The living conditions are quite precarious for many families, because they are forced to rent places with limited water storage and supply, and sanitation facilities that lack the necessary privacy and location to ensure proper hygiene. The pressure on resources, such as water, electricity, health care, education and waste management, has significantly increased. Most families (both Syrian and Jordanian) must regularly pay for water transport and bottles due to the irregular network distribution.

Additionally, the Jordanian government has been reluctant to grant work permits to refugees, thereby reducing job competition with nationals. As a result, most refugees can only be employed informally with lower wages. Many families from both communities experience a deficit between income (including existing assistance) and expenditure, leading to debt and the selling of assets to survive. Coping strategies have been seriously eroded as time passes, and most vulnerable households are unable to meet their basic needs.

\section{Mental health and psychosocial needs}

Many refugees were exposed to risk factors, such as witnessing violence in Syria, losing family members and relatives, housing and assets or having family members or friends wounded or disappeared. Upon arrival in the host country, they are confronted with additional risk factors related to poverty, problems (including abuse by someone from the family or another person) and a loss of the traditional points of reference, social networks and support. These factors have led to psychological distress exacerbated by uncertainty about their future (no short- or midterm visibility on the crisis' resolution) and the future of neighbouring countries (political unrest in Egypt, repeated tensions in Lebanon and acute violence in Iraq). According to the assessment conducted by the Eastern Mediterranean Public Health Network (EMPHNET) in Jordan (EMPHNET, 2013) among camp and non-camp residents, the main signs of distress expressed by respondents were fear $(15.1 \%)$, anger $(28.4 \%)$, apathy $(25.6 \%)$, hopelessness (26.3\%), upset about the conflict leading to avoidance (38.1\%) and inability to perform essential daily activities (18.8\%). Moreover, $17 \%$ of families reported episodes of nocturnal enuresis among children aged 2-12 years at least twice in the two weeks before the study. Other concerns were also reported, such as excessive nervousness, social isolation, continuous crying and somatic complains (e.g. headaches).

Subsequent assessments and studies have shown the psychosocial impact of the crisis and the displacement of people directly affected by them, such as the study conducted by International Medical Corps (IMC) in December 2014 on the mental health and psychosocial needs of adolescent refugees in Jordan. The main findings show that adolescent Syrians experience a great deal of loss and longing for their homes in Syria. They maintain the perception of being discriminated against by host populations, and experience bullying and intimidation, anger and nightmares, abuse or witnessing other children being abused and constant worry and nervousness. They also reported an increase in family violence by parents. The same organisation reported on the most common mental health problems among the Syrian population who presented to outpatient clinics. On the basis of internal monitoring data from March to October 2014, 74\% of the patients managed in Jordan corresponded to severe emotional distress, including depression and anxiety.

The most recent needs assessment took place in November 2015 by IMC and Sisterhood is Global Institute to explore the extent of mental health and psychosocial concerns among the refugee population, and for the first time, also among host communities. The main findings revealed an increased expression of distress compared to the results in 2013 as respondents reported the high levels of fear $(33.5 \%$ of Syrians and $20 \%$ of Jordanians), anger (47\% of refugees and $25 \%$ Jordanians), hopelessness (32\% refugees and $19 \%$ Jordanians) and an inability to perform essential daily activities (33\% refugees and 25\% Jordanians) (IMC \& Sisterhood is Global Institute, 2015). These results show the extent of the impact of violence, displacement and hardship on people's ability to function; to take care of themselves and others; to keep or develop social links; and to cope with the changes due to precarious living 
conditions and a different environment (new country, refugee status and the lack of information on available services). Men feel particularly guilty for being unable to protect their families and to provide the minimum financial resources. Many teenagers are contributing to the household's income, which puts additional pressure on them as the family's bread winner.

\section{Social tensions and coping strategies}

Jordanian families initially showed a great deal of solidarity towards refugees, but as the crisis becomes more and more protracted, this has been decreasing, and tensions have been rising between both communities, especially around competition for resources. Syrians are feeling stigmatised by locals who blame them for the deterioration of the social and economic environment. Jordanians, especially the most vulnerable, are directly affected by the large influx of refugees, because more people are applying for the same jobs, there are increased rents, overstretched public services (school, health facilities, waste management, etc.) and feelings of anger and jealousy towards the assistance provided to Syrians (CARE International, 2016; REACH, 2014).

As a consequence, many refugees do not participate in the social life of the community, because they would rather stay at home and have only contact with close neighbours. The number of refugees settling in some areas because of pre-existing family or business relations is decreasing, and this reduces the financial support they could get from this social network. Some children attend school, but many do not feel integrated, leading to them dropping out and resulting in fewer opportunities to play and socialise with other children. Adolescent refugees report that their main concerns are harassment (verbal and physical) and discrimination in non-camp settings, as well as feeling unwelcome in schools (IMC, 2014).

The main livelihood coping strategies reported by CARE International (2016) include borrowing money, humanitarian assistance, selling properties and receiving support from the host community. Rising tensions have been forcing refugees to deploy non-adaptive strategies, such as social isolation (especially for women, teenagers and children who dropped out of school) and forced marriage (mainly for girls), because the number of early marriages had a sharp rise in 2013 (25\%) and the first quarter of 2014 (31.7\%) (CARE International, 2016; UNICEF, 2014). Child labour $(6.2 \%)$ and adult or child begging $(3.1 \%)$ were also reported as ways to meet basic food needs by the respondents of CARE's assessment (2016). The increase in domestic violence by adults towards children and by men against women was another unhealthy coping mechanism to channel frustration (ibid.). Drug abuse and resorting to crime were other forms of dealing with hardship (World Vision International, 2015).

In summary, the main drivers of current social tensions are among structural causes prior to the crisis in Syria, socioeconomic causes and proximate causes, which are driven by displacement (World Vision International, 2015).
Authorities, humanitarian actors and host communities are faced with challenges, because they have to adjust to long-term economic and demographic shifts, given the protracted crisis.

\section{Psychosocial interventions to promote peacebuilding and social cohesion}

One of the challenges imposed by protracted crisis is how to promote social cohesion and integration, defined as 'the nature and set of relationships between individuals and groups ( . . . ) in a particular environment' (World Vision International, 2015) while alleviating the tensions between refugee and host communities in non-camp, urban settings. Social cohesion should be an area of greater growth in humanitarian and development programming, and psychosocial interventions can be used for that purpose within the framework of processes involved in social transformation and peacebuilding during protracted conflict.

Hamber, Gallagher, and Ventevogel (2014) argue that psychosocial work may serve the promotion of peacebuilding and the other forms of social change. Activities that involve contact between people and participating in joint activities, artistic or others for instance, constitute a form of building peace (ibid.). According to Allport's (1954) contact hypothesis (as cited by American Psychological Association [APA], 2012, p. 55), 'bringing people together can simultaneously reduce bias and promote positive relations', subject to the following conditions being met: 'equal status, personal interaction, cooperative activities toward a shared goal, and social norms endorsed by relevant authorities that favour inter group contact' (ibid., p. 67). Facilitating inter-personal interactions and cross-group friendships is one of the strategies studied to overcome prejudice and mitigate its consequences, because it provides the opportunity to develop positive emotional reactions in relation to the other group (ibid.). The metaanalysis conducted in 2006 by Pettigrew and Tropp (ibid.) to examine the investigations of the effects of inter-group contact in different settings showed that it reduces intergroup bias and prejudice - especially for the majority of group members - under specific conditions, and it does so more effectively if the groups depend on each other cooperatively, if the groups are recognised as having equal status and if authorities encourage inter-group contact.

The processes of social change and peacebuilding must take into account the importance of addressing individual psychological needs and resources as a precondition or preparatory work for individuals to be ready to engage in those processes (Hamber et al., 2014; Hart \& Colo, 2014). Psychosocial interventions may offer the necessary space to find psychological relief and regain a sense of control over one's life, increasing personal capacities and resources to bounce back and to get involved (ibid.; Eiling, Van Diggele-Holtland, Van Yperen, \& Boer, 2014). Lambourne and Gitau (2013) stress the need for considering such interventions as being a part of a 'more holistic and transformative approach to peacebuilding that promotes resilience, social cohesion (... )' (p. 23). In settings of armed conflict, individuals function in very toxic social 
environments that constitute the primary determinants of people's mental health issues and distress as a consequence of being exposed to risk factors at all levels of society (Bubenzer \& Tankink, 2015).

ACF's approach to psychosocial support is one that focuses on personal, family and community resources that can be mobilised to further coping, resilience and adaptation. The approach also emphasises the importance of taking into account the social context where people function and how this context determines risk and protective factors (ACF, 2009), entering into social healing processes and dynamics. This paper presents the work that the organisation performed from January 2014 to January 2016 in Irbid Governorate, Jordan.

\section{Programme Description}

ACF implemented a psychosocial support programme, reaching over 7000 people from both refugee and host communities, in over ten villages in the districts of Ramtha, Bani Ubaid, Mazar Shamali, Bani Kinanah, Korra and Irbid city. Initially, the organisation set up psychosocial centres to operate from January to September 2014. At that time, ACF signed agreements with several community-based organisations to jointly propose activities within their centres, involving people from both communities as volunteers for the identification and facilitation of participants.

\section{Objectives}

The programme was designed to tackle multisector issues with the aim of improving the living conditions of the members of the refugee and host communities in Jordan affected by the Syrian crisis. The response strategy included actions on water supply, sanitation and hygiene, cash assistance and psychosocial support to increase the healthy coping mechanisms of affected people, particularly vulnerable households, and to facilitate access to basic services. The psychosocial support component's purpose was to improve the people's sense of well-being, reduce distress produced by traumatic events and current difficult living conditions and to foster resilience. It also aimed at making available safe social spaces to break through isolation, to increase social support and to promote healthier interactions between refugees and the members of the host community, with the hope of reducing social tensions between the two groups.

\section{Participants}

The participants belonged to vulnerable households from both communities, specifically pregnant and lactating women; parents with young children; women heads of households or lacking family support; young people; and those demanding psychological care or referred by other organisations. They were identified based on UNHCR's list of registered refugees, through community volunteers for those who were not registered, and through the National Aid Fund from the Ministry of Social Development (in the case of Jordanian families in a situation of vulnerability). Participation was proposed in common activities and group sessions involving 10-12 people with groups formed based on mutual characteristics (e.g. pregnancy, parents of young children, etc.). Both parents of young children were encouraged to join the groups, with an emphasis on parenting; however, the majority were mothers. Girls and boys, as well as female and male adolescents, participated equally in the groups dedicated to them. Two types of groups were organised: maternal and child care practices with pregnant and lactating women and parents with young children; and group support for adults, single mothers, parents of children suffering from enuresis, adolescents and children.

\section{Programme team}

The team included local psychologists, psychosocial workers (no specific qualification required, because training and supervision was given by a senior psychologist) and a midwife. Most of them were Jordanian nationals. However, it was possible to recruit some Syrian nationals in spite of the constraints of work and residency permits. A senior psychologist, initially an international staff member followed by a member of the national staff, was in charge of the programme, team management and supervision.

\section{Child and maternal care practices}

The groups would meet once a week for five to six sessions over two months. The methodology applied in the sessions followed activity guides developed for pregnant and lactating women, and they consisted of exercises aimed at breaking the ice between participants; creating a safe space to facilitate expression and sharing; and raising awareness about maternal health. They covered pregnancy stages and danger signs indicating the need to seek health care, healthy nutrition and preparing for delivery while addressing fears and concerns and the psychosocial and health benefits of breastfeeding for mother and child.

Specific groups with the parents of young children were organised with the purpose of promoting parent-child interactions, bonding and stimulation through playing and massaging. These sessions involved guidance on adapted games and toys, including toy making, according to the child's developmental stage and parents' available resources. Discussions would take place at the end of every session about the importance of stimulation for children's optimal growth and development, challenges in communication, complementary feeding and resources for care within the family structure.

\section{Psychological and group support}

These groups, mentioned above, would also meet once a week for five to six sessions, and the methodology included role playing, group discussions, relaxation techniques, breathing exercises and case studies. Some groups had the objective of covering parenting skills, education for children in Jordan, communication skills and anger management. The activities proposed in every session allowed for experience sharing related to discrimination; discussions on how parents may support their children facing 
discrimination or bullying at school; and identification, encouragement and praising positive behaviour in children. One of the sessions would focus on sensitising and awareness raising regarding the impact of domestic violence and violence against children within the family. Other groups were structured specifically for women head of households or those lacking family and social support to provide the opportunity for women to interact with those in similar situations and to encourage mutual support. In addition to specific sessions, they covered stress management and guided exercises on positive thinking, self-esteem and self-confidence. The parents of children suffering from secondary enuresis could also take part within a dedicated support group where participants were guided through the recognition of feelings, coping with strong emotions and supporting their children.

During discussion, participants were given the opportunity to express concerns and feelings about their families. Topics on life stressors (e.g. rent, food and work) raised the tensions among participants. Jordanians expressed their impression that because of the refugees, all prices had risen sharply. The psychosocial moderators were trained in active listening and conflict mediation to be able to acknowledge everyone's emotions and feelings, while emphasising the need to respect everyone's point of view, thereby showing empathy and defusing tension.

Another sensitive subject was the discrimination and bullying of Syrian children in local schools. Parents were particularly concerned because it appeared to be on the increase. The discrimination against their children had been affecting families, and many children refused to register in Jordanian schools. Refugees were also highly concerned about their access to health services given the fact that the Jordanian government was struggling to provide free health care for everyone, including the increased flow of refugees.

Participants who needed more time and space to express their concerns and sorrows were given the possibility of speaking privately with one of the psychosocial workers, who would assess need and requirement for individual counselling with a psychologist.

According to the type of group, the team developed guidelines for each session for the facilitators to know the steps to follow and when to use specific activities or techniques. Guidelines for sessions with adolescents, from the families taking part in support groups, were developed to address adjustment difficulties related to this age and to the host country (in the case of Syrian adolescents); the feelings of isolation and discrimination; and the loss of social relations in the home country. The sessions applied a support group approach, according to which participants actively proposed the topics or matters to discuss. In addition, ice breakers and energisers were introduced to create a group dynamic. The participants reported having enjoyed the opportunity to have social relations with people from other communities and to discuss topics relevant to their age group, future plans and communication with their parents, as well as to have activities dedicated to their needs. The team faced some challenges at the beginning because some Syrian parents were worried about their children being exposed to mistreatment by Jordanian adolescents. However, as soon as they started to get to know each other, they were able to get along and mingle easily. Some friendships started there, and some of them would even come to the centres together.

Young children coming with their parents would join group sessions that would meet once a week for five to six weeks, providing them with a safe space and therapeutic guidance on emotional expression through colouring, drawing, clay modelling, singing, dancing and role play. Children from both communities did not have any problems relating to each other, in spite of the fact that Syrian children were experiencing difficulties adapting to their new environment and were showing signs of distress, in addition to children from Jordanian families encountering daily constraints (e.g. their families did not have enough money to buy food or materials that would allow them to go to school).

In addition, ACF organised weekly gatherings with a twofold objective: to introduce and explain the programme in every mentioned village and to facilitate exchanges between Syrian and Jordanian people. The gatherings took place in or out of the centres, and they allowed participants from both communities to get to know each other and to have more opportunities for interaction and discussion. Some people showed the expected reluctance in the beginning, but as time went by and they got to know each other, relationships improved.

\section{Programme evaluation}

The programme was evaluated with the purpose of assessing participants' satisfaction and how they perceived its effectiveness. Focus group discussions (FGDs) were held at the end of every funding cycle (every six to eight months). The first phase of evaluation (July 2014) was conducted with the participants who were present at the last session. The focus groups were conducted by the same psychosocial workers in charge of facilitating the sessions, using a list of questions covering their perception of improvement of well-being and their children's well-being; the benefits of participating in terms of meeting other people, breaking isolation, getting new information or knowledge, learning new practices, sharing experiences, having a listening, quiet and safe space and learning about parent and child bonding; what they liked the most and the least; their favourite subjects; and if there were any problems and suggestions for improvement. The team also gathered spontaneous comments from participants in their weekly reports.

The second phase of evaluation took place in May 2015. Eleven focus groups were conducted by the senior psychologist with 110 participants selected randomly from different support groups, with them participating in at least four sessions. The facilitation guide covered what they liked the most from the sessions; if there was something discussed or learned from the sessions that they implemented in their daily life; a story that would describe the 
most significant change that was a result of the first time they came in touch with ACF's team; how they evaluated the collaboration with ACF's team; if there were challenges related to transportation, the location of activities, etc.; and if they had any suggestions. The last phase of evaluation (December 2015) included a FGD with 14 participants that were selected randomly by the monitoring and evaluation team. It was conducted jointly by a psychosocial worker and a member of the monitoring team, and the guide covered similar questions to the ones from the previous evaluation phase. The focus groups of the last two phases included members from both communities combined. The feedback, opinions and attitudes gathered on all phases were analysed using an emergent coding system by main themes and by the type of support group.

According to the feedback, the group sessions helped them brake their isolation, as well as be aware of and pay more attention to the positive and common characteristics of both communities (refugee and host). For instance, women that participated in support groups, especially for heads of households (divorced, single parent or widow) or without family and social support, reported they had been feeling very secluded before joining the groups, and that these gave them the chance to meet other women who shared the same challenges and struggles. They have been able to build new friendships and strengthen their contacts with neighbouring women in the villages. As a result, their feelings of isolation and loneliness decreased (e.g. the results of the first evaluation phase showed that $73 \%$ of the women stated that it helped them to meet other people, and $52 \%$ of them said that it specifically helped them to break isolation). Moreover, they expressed feeling stressed due to the great responsibility they bear to support their families all by themselves and that they found comfort in listening to the experiences of other women in the group sessions, as well as learning problem-solving skills and anger management.

Fathers and mothers having participated in the parenting groups stated that they had been facing challenges in communicating with their children and understanding their needs, before joining. They reported being encouraged to assume a listening attitude with their children, and to spend more time talking and interacting with them as a benefit of the sessions. They also declared observing changes in their children's behaviour, such as less aggressiveness and stubbornness. Moreover, they claimed that the relaxation exercises learned helped them manage stress and anger more appropriately in their daily lives, in addition to having felt safe in the sessions and able to express their feelings and concerns. The mothers of infants that took part in the specific sessions reported that through learning how to massage and playing with their babies, they experienced the strengthening of their bond, as well as understanding their needs better. Pregnant women pointed out the benefit of coping better with pregnancy as a consequence of gaining new information and feeling reassured while sharing with others.

Adolescents reported feeling more self-confident and able to express their feelings positively, not only with their peers, but also with their parents after joining the groups dedicated to them. Moreover, as a result of their involvement in the organisation and facilitation of the groups with young children since October 2015, they stated having a greater sense of responsibility towards their communities.

Finally, the integration of Syrian nationals as members of the team proved to be successful, because it helped the rest of the team understand better what it is like to be displaced and the difficulties faced in the host country. Participants also appreciated having members of their community supporting them throughout the sessions, because it made them feel embraced and understood.

\section{Limitations}

One major limitation of the programme was the short duration of around six months in each village. This had an impact on the work of the team in raising awareness about the purpose and benefits of psychological and psychosocial support as, once beneficiaries were engaged, there was little time left to hold enough sessions with them. This was the case with the people involved in group support, because this was new to them and their participation was not always regular. Some people did not return after participating in one or two sessions, especially during the first funding cycle, because of expectations related to the cash assistance component. Ramadan prevented some people from coming back to group sessions. Transportation to the centres was another difficulty, because many people could not afford the taxi fare and did not live within walking distance. Subsidy for transportation was provided to some families as the budget allowed. In other cases, the team paid home visits to people who could not come to the centres (e.g. pregnant women in their last trimester, people with functional limitations, etc.). Some women could not come without permission from their husbands.

The activities schedule was adapted according to the schools' shifts system. However, some schools had a morning shift for Jordanians and an afternoon one for Syrians. This system made it very challenging for the team to integrate children from both communities. Male and female adolescents were interested in participating, but they faced some challenges, especially in villages where mothers expressed concerns about their daughters going out of the house on a regular basis and without company, and with some male adolescents being employed, which prevented them from participating in activities or from participating at all. The groups dedicated to adolescents saw an equal participation of males and females. However, men were significantly less participative than women in the support groups, in spite of being identified as at risk for psychological distress by some needs assessments. Finally, the experiences of trauma were mainly discussed within individual counselling sessions, because some people did not feel free to express their feelings due to the belief that others who have not experienced war trauma could not understand. 


\section{Conclusion}

The programme contributed to social cohesion as participants claimed positive effects, such as increasing communication, mutual understanding and socialisation between the members of both communities. This allowed them to reduce their isolation, expand their social support networks, find psychological relief, improve their well-being and build their self-confidence. The tension between participants could be relieved and tackled within a therapeutic and structured setting, making dialogue possible. The focus was on personal, family and community resources that could be mobilised to cope and adapt to their current situation.

These outcomes were in line with the social contact hypothesis formulated by Allport (1934) (in APA, 2012) to reduce inter-group conflict, because participating in common activities may reduce bias and cultivate positive relations. The programme facilitated inter-personal interactions and crossgroup friendships to encourage cohesion and harmony and to contribute to reducing prejudice, especially on the part of Jordanian participants who held negative attitudes towards refugees. The support groups were able to induce empathy and reduce anxiety about the outgroup by stating common characteristics and shared problems.

However, it has been established that simple contact is not enough (APA, 2012), and in the case of the programme in question, meta-analysis informed that cooperative activities towards a shared goal (e.g. community gardens for food security) coupled with greater support from authorities would have made a bigger impact. Moreover, the extent to which social tensions were diminished beyond the limits of the safe spaces were not captured, and a more in-depth study in developing empathy and sensitivity among participants would have been necessary. This would better illustrate the complexity of inter-relationships and generate insights into links, relationships, bonds and conflicts for people to develop a greater sense of unity and reliance in each other. Finally, the intra-group healing of collective trauma (Somasundaram, 2014) as a first step could have helped participants to move forward and use the support groups to share their narratives with the members of the host communities and engage in larger initiatives of social mediation and concurrence. This programme fostered social cohesion involving people in activities as a contribution to social change and peacebuilding within a context of protracted crisis.

\section{Financial support and sponsorship}

Nil.

\section{Conflicts of interest}

There are no conflicts of interest.

\section{References}

Action Contre la Faim [ACF]. (2009). Policy on mental health and child care practices. Paris: Author. Retrieved from http://www.actioncontrelafaim.org/sites/default/files/publications/fichiers/acf_mhcp_policy_2009_gb.pdf

Action Contre la Faim [ACF]. (2013). Jordan assessment report (Unpublished internal report). Paris: Author.

American Psychological Association [APA]. (2012). Presidential task force on preventing discrimination and promoting diversity. In Dual pathways to a better America: Preventing discrimination and promoting diversity. Washington, DC: Author.

Amnesty International. (2016). The state of world's human rights (Annual report). Retrieved from https://www.amnesty.org/en/documents/ pol10/4800/2017/en/

Bubenzer, F., \& Tankink, M. (Eds.). (2015). Proceedings from Healing communities, transforming society. Exploring the interconnectedness psychosocial needs, practice and peacebuilding. Institute for Justice and Reconciliation \& War Trauma Foundation. Retrieved from http:// ijr.org.za/home/wp-content/uploads/2016/11/IJR-Healing-communities-conference-WEB.pdf

CARE International. (2016). Six years into exile. The challenges and coping strategies of non camp Syrian refugees in Jordan and their host communities. Amman: Author.

Eastern Mediterranean Public Health Network [EMPHNET]. (2013). Assessment of mental health and psychosocial support needs of displaced Syrians in Jordan. Amman: Author.

Eiling, E., Van Diggele-Holtland, M., Van Yperen, T., \& Boer, F. (2014). Psychosocial support for children in the Republic of South Sudan: An evaluation outcome. Intervention, 12(1), 61-75.

Hamber, B., Gallagher, E., \& Ventevogel, P. (2014). Narrowing the gap between psychosocial practice, peace building and wider social change: An introduction to the special section on this issue. Intervention, 12(1), 7-15.

Hart, B., \& Colo, E. (2014). Psychosocial peacebuilding in Bosnia and Herzegovina: Approaches to relational and social change. Intervention, 12(1), 76-87.

IMC, \& Sisterhood is Global Institute. (2015). Mental health and psychosocial support needs assessment of displaced Syrians and host communities in Jordan. Washington, DC: IMC.

International Medical Corps [IMC]. (2014). Mental health, psychosocial and chid protection for Syrian adolescent refugees in Jordan. Washington, DC: Author.

Lambourne, W., \& Gitau, L. W. (2013). Psychosocial interventions, peacebuilding and development in Rwanda. Journal of Peacebuilding and Development, 8(3), 23-36.

REACH. (2014). Understanding social cohesion and resilience in Jordanian host communities: Assessment report. Geneva: Author.

Somasundaram, D. (2014). Addressing collective trauma: Conceptualisations and interventions. Intervention, 12(1), 43-60.

Syria Regional Refugee Response: Interagency Information Sharing Portal. (n.d). Retrieved from http://data.unhcr.org/syrianrefugees/ regional.php

UNHCR. (2013). Syria Response Plan 5. Retrieved from http://www. unhcr.org/partners/donors/51b0a56d6/syria-regional-response-planupdate-5-full-document.html

UNICEF. (2014). A study on early marriage in Jordan. Amman: Author

United Nations. (2014). Syria regional response plan. Jordan chapter. Retrieved from http://data.unhcr.org/syrianrefugees/documents.php? page $=1 \&$ view $=$ grid $\&$ Language $\% 5 \mathrm{~B} \% 5 \mathrm{D}=1 \&$ Type $\% 5 \mathrm{~B} \%$ $5 \mathrm{D}=10 \&$ Country $\% 5 \mathrm{~B} \% 5 \mathrm{D}=107$

World Vision International. (2015). Social cohesion between Syrian refugees and urban host communities in Lebanon and Jordan. Uxbridge, Middlesex, UK: Author. 